\title{
Confirmation of beach accretion by grain-size trend analysis: Camposoto beach, Cádiz, SW Spain
}

\author{
Emmanuel Poizot • Giorgio Anfuso • Yann Méar • \\ Carlos Bellido
}

Received: 25 January 2013 / Accepted: 26 February 2013 /Published online: 15 March 2013

(C) Springer-Verlag Berlin Heidelberg 2013

\begin{abstract}
An application of the grain size trend analysis (GSTA) is used in an exploratory approach to characterize sediment transport on Camposoto beach (Cádiz, SW Spain). In May 2009 the mesotidal beach showed a well-developed swash bar on the upper foreshore, which was associated with fair-weather conditions prevailing just before and during the field survey. The results were tested by means of an autocorrelation statistical test (index I of Moran). Two sedimentological trends were recognized, i.e. development towards finer, better sorted and more negatively skewed sediment (FB-), and towards finer, better sorted and less negatively or more positively skewed sediment $(\mathrm{FB}+)$. Both vector fields were compared with results obtained from more classical approaches (sand tracers, microtopography and current measurements). This revealed that both trends can be considered as realistic, the FB + trend being identified for the first time in a beach environment. The data demonstrate that, on the well-developed swash bar, sediment transported onshore becomes both finer and better sorted towards the coast. On the lower foreshore, which exhibits a steeper slope produced by breaking waves, the higherenergy processes winnow out finer particles and thereby produce negatively skewed grain-size distributions. The upper foreshore, which has a flatter and smoother slope, is
\end{abstract}

E. Poizot $(\bowtie) \cdot$ Y. Méar

Conservatoire National des Arts et Métiers, Laboratoire

Universitaire des Sciences Appliquées de Cherbourg LUSAC, Cnam/Intechmer, 50100 Cherbourg, France

e-mail: emmanuel.poizot@cnam.fr

G. Anfuso $\cdot$ C. Bellido

Department Ciencia de la Tierra, Facultad de Ciencias del Mar y Ambientales, Universidad de Cádiz, Polígono Río San Pedro s/n, 11510 Puerto Real, Spain controlled by lower-energy swash-backwash and overwash processes. As a result, the skewness of the grain-size distributions evolves towards less negative or more positive values. The skewness parameter appears to be distributed as a function of the beach slope and, thus, reflects variations in hydrodynamic energy. This has novel implications for coastal management.

\section{Introduction}

Coastal development works have greatly expanded over the past decades and some $50 \%$ of the world's coastline is currently under threat because of excessive anthropogenic pressure (e.g. Finkl and Kruempfel 2005). Moreover, touristic activities, especially the market linked to 'sun, sea and sand' (3S), have been strongly affected by natural coastal processes such as erosion and flooding related to climate change and involving, for example, sea-level rise (SLR) as well as increases in storm frequency and intensity (e.g. Karl and Knight 1998; Poore et al. 2009; Garrison et al. 2012 for the USA; Castelle et al. 2008 for Queensland, Australia). In Europe, the fastest growth in coastal urbanization between 1990 and 2000 took place on the Mediterranean and Atlantic seaboards of Portugal (34 \%) and Spain (18 \%), followed by France, Italy and Greece (EEA 2006). Along the Iberian Peninsula coastline, where the present study was performed, this is posing an ever-increasing challenge to coastal management, as well as research in present-day and projected beach morphodynamics (e.g. Flor-Blanco et al. 2013; Sancho-García et al. 2013).

This trend is observed also in the province of Cádiz in SW Spain, a coastal sector which would be at risk during future SLR (e.g. Fraile-Jurado and Ojeda-Zújar 2013) and where the $3 \mathrm{~S}$ market represents a major economic asset 
linked to the extensive use of beaches by tourists, especially during the summer months. At present, beaches and associated economic activities are threatened by erosion and resulting beach retreat locally exceeding $1 \mathrm{~m} \mathrm{year}^{-1}$ (Anfuso et al. 2007). To counteract coastal retreat, and especially to make beaches more attractive by enlarging the dry beach width, the beaches of Cádiz were nourished during the 1990s by about 13 million $\mathrm{m}^{3}$ of sediment, at a total cost of US\$ 37 million (Muñoz et al. 2001).

Numerous methods can serve to evaluate the effectiveness of such measures by studying the spatial and temporal evolution of these sedimentary beach environments. Among these, the Sediment Trend Analysis $\left(\right.$ STA $\left.^{\circledR}\right)$ method (McLaren 1981; McLaren and Bowles 1985) uses statistical parameters (mean grain size, sorting and skewness) derived from granulometric data to generate transport vectors. As pioneers, McLaren (1981) and McLaren and Bowles (1985) applied this approach to validate their hypotheses of sediment transport directions. In fact, beaches were among the first environments to be studied by this method. Thus, based on a relatively small number of samples, Masselink (1992) applied the STA ${ }^{\circledR}$ method to a beach in southern France, but without success (Masselink 1993; McLaren 1993). Although succeeding in defining a trend vector field in another beach environment based on a larger dataset, Guillén and Palanques (1996) nevertheless concluded that the sedimentary dynamics of a large beach could not be reliably determined with the $\mathrm{STA}^{\circledR}$, and recommended studying smaller homogeneous areas. Pedreros et al. (1996) took this recommendation into account and applied a grain size trend analysis (GSTA) - a twodimensional variety of the STA ${ }^{\circledR}$ method proposed by Gao and Collins (1992) - to an area of reduced size. They demonstrated that the GSTA approach was an excellent tool to identify sediment transport direction. On the other hand, Masselink et al. (2008), still using the $\mathrm{STA}^{\circledR}$ method, assessed an intertidal beach in a similar environmental context and concluded that the sediment trend model failed to reproduce small-scale transport patterns. These partly contradictory results suggest that, in beach environments, the GSTA is more suitable than the $\mathrm{STA}^{\circledR}$ to determine sediment transport directions and that it has potential for further refinement.

The main aim of the present study was to evaluate the usefulness of an improved GSTA method proposed by Poizot et al. (2006) and Poizot and Méar (2008, 2010), which was tested in a field assessment carried out during a tidal cycle at Camposoto beach in SW Spain. The resulting sediment transport vector fields were then compared with data obtained from independent, reliable but more timeconsuming methods - fluorescent tracers, microtopography and current measurements - by Bellido et al. (2011).

\section{Regional setting}

The investigated coastal sector forms part of Camposoto beach, which faces the Atlantic Ocean in the province of Cádiz (SW Spain, Fig. 1). It comprises a broadly N-Soriented coastal spit consisting of quartz-rich beach sand, salt marshes and dune ridges locally breached by washover fans. During the field assessment in early summer of 2009, the beach showed a well-developed swash bar (terminology according to Carter 1988) which was migrating landwards and welding to the upper foreshore.

The tidal regime is mesotidal with ranges of 3.2 and $1.1 \mathrm{~m}$ at spring and neap tides respectively, and exhibits a semidiurnal periodicity. The most severe storms are linked to westerly winds which are generally related to Atlantic low-pressure systems, the associated winds having a mean annual speed of $16 \mathrm{~km} \mathrm{~h}^{-1}$ with a frequency of $13 \%$. Easterly and southeasterly winds, originating in the Mediterranean Basin, have an annual frequency of $20 \%$ and mean speed of $28 \mathrm{~km} \mathrm{~h}^{-1}$, which is greatly increased locally due to funnelling through the Strait of Gibraltar. Wave heights display substantial seasonal variation, whereas wave periods are almost constant throughout the year. Significant wave heights are usually lower than $1 \mathrm{~m}$ and, during storms, exceed $2.5 \mathrm{~m}$ (RangelBuitrago and Anfuso 2011). Due to coastline orientation and the predominant wave fetch direction, the main longshore drift is towards the southeast.

Fair weather prevailed on days before and during the field survey at Camposoto beach, the data being recorded during spring tide on 8 May 2009 from the morning low tide $(9: 24 \mathrm{~h})$ to the evening low tide $(21: 43 \mathrm{~h}$; Bellido et al. 2011). Swell waves were recorded with mean $\left(H_{\mathrm{bm}}\right)$ and significant $\left(H_{\mathrm{bs}}\right)$ breaking wave heights of 0.16 and $0.20 \mathrm{~m}$ associated with periods of 7 and $9 \mathrm{~s}$ respectively. The waves approached from the southwest and gave rise to shoreparallel currents flowing north-westwards. The wind conditions during the field survey were not recorded.

In that earlier study, accretion processes related to swell waves produced a beach profile pivoting around mean water level, with erosion on the lower foreshore and accumulation on the upper foreshore. Specifically, higher accretion values (about $12 \mathrm{~cm}$ ) were recorded on the seaward side of the bar and lower values on the bar top and landward side (about $2 \mathrm{~cm}$ ). By the end of the field survey of ca. $12 \mathrm{~h}$, the bar had migrated about $50 \mathrm{~cm}$ landwards.

\section{Materials and methods}

Disturbance depth and sediment transport

For the benefit of the reader, the fluorescent tracer, microtopography and current measurement methods used 
by Bellido et al. (2011) are summarized briefly here. Beach topography was surveyed by means of an RTK-GPS. Microtopographic changes and disturbance depths were determined during each morning low tide by measuring the vertical accretion or erosion relative to the position of loosely fitting washers placed over 25 steel rods inserted into the beach (Fig. 1; also see Anfuso 2005). Waves and currents were monitored by a pressure transducer and an electromagnetic current meter respectively. Following Komar and Inman (1970), fluorescent tracers served to investigate longshore and cross-shore transport and disturbance depth.

To study tracer dispersion and grain-size characteristics, 65 cores were taken during the night low tide using PVC pipes of $20 \mathrm{~cm}$ length and $5 \mathrm{~cm}$ diameter. In the laboratory, the cores were split and then cut into 2-cm slices which were dried in the open air and weighed on a balance with a precision of $0.01 \mathrm{~g}$. In each of the seven slices selected for the study, marked fluorescent grains were manually counted under an ultraviolet lamp and the results evaluated by means of the spatial integration method (Komar and Inman 1970). The location of the centroid-i.e. the average position of the mass dispersion of the tracer-was calculated for each $2-\mathrm{cm}$ depth interval, as well as for the seven intervals combined. The thickness of the active sand layer-i.e. the area of the beach cross-section affected by hydrodynamic processes during the field assessment-was calculated according to disturbance values recorded with the rod and washer method. Sand transport was determined considering the position of the centroid and the area of the active sand layer (Komar and Inman 1970; Bellido et al. 2011). Furthermore, the present study makes use of a novel dataset comprising the grain-size distributions of 65 surficial (uppermost $2 \mathrm{~cm}$ ) beach samples analysed by means of a 2 -m-high settling tube filled with distilled water. Three runs per sample were carried out and the standard grain-size distribution statistics (mean, sorting and skewness) were obtained using the moment method.

\section{Grain-size trend analysis}

McLaren (1981) and McLaren and Bowles (1985) used the mean, sorting and skewness in applying the STA ${ }^{\circledR}$ in a onedimensional approach. In terms of these statistical parameters, sediment grain size can become either finer $(\mathrm{F})$ or coarser (C), the sorting can become either better (B) or poorer $(\mathrm{P})$, and the distribution can become either more negatively $(-)$ or more positively $(+)$ skewed. In the twodimensional GSTA of Gao and Collins (1992), the sitespecific mean, sorting and skewness are compared with corresponding values at neighbouring locations in all directions. Using geostatistical tools, Poizot et al. (2006) slightly modified the initial Gao and Collins (1992) method, and Poizot and Méar (2010) developed a computer program which opens up new perspectives for GSTA investigations.

Following the workflow of Poizot and Méar (2008, 2010), sand transport vector fields on Camposoto beach were computed using the freely available GiSedTrend software (http:// www.geoceano.fr/accueil/la_recherche/item_1_/gisedtrend), a plug-in of QGIS (Quantum GIS Development Team 2012), and a geographical information system (GIS) software. To
Fig. 1 Locations of sediment samples on Camposoto beach. $M W L$ Mean water level, $H W L$ high water level, $L W L$ low water level

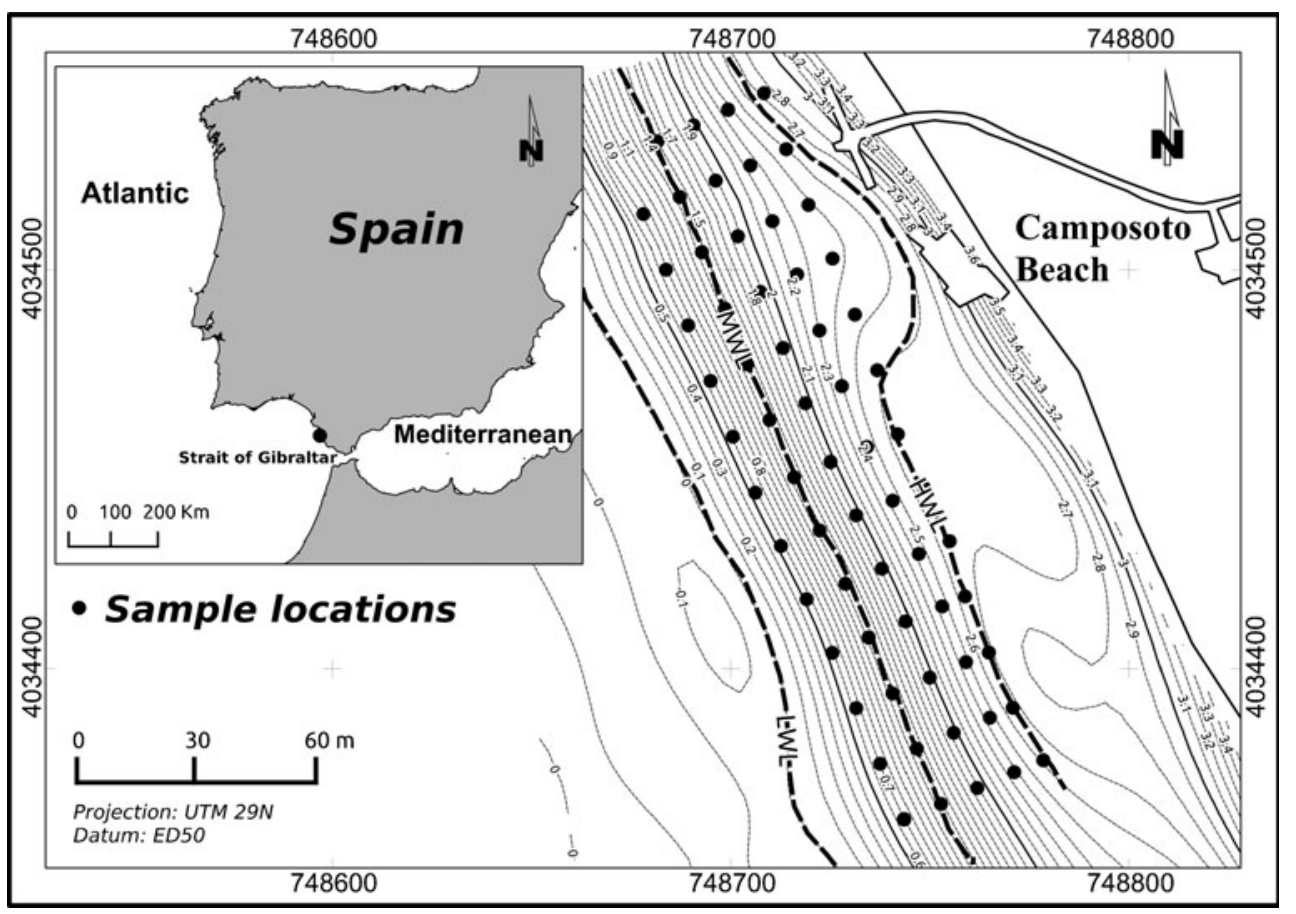


determine a trend vector field, three main steps are required: (1) generation of a regular grid, (2) choice of a characteristic distance and (3) choice of trend case(s).

\section{Regular grid generation}

The number of sediment samples to be analysed is subject to economic and practical considerations. Because the number of collected samples and the distance between sampling points vary, the relative influence (weight) of each sample also varies over the study area. Asselman (1999) based her work on regular raster grids obtained after the interpolation of statistical parameters. This approach offers the advantage of keeping the same weight for each of the neighbours and skipping the filtering step recommended by Gao (1996). In the present study, regular grids were produced for each statistical parameter, with a slightly higher density of points than in the original grid. Wilcoxon tests were conducted to check whether the interpolated grid differed from the original dataset in terms of information content (cf. Poizot et al. 2006; Poizot and Méar 2008).

\section{Characteristic distance}

The "characteristic distance" is defined by the number of neighbouring sample points taken into account when determining a trend vector at a particular sample location. Gao and Collins (1992) called this distance "the mean spatial scale of sampling". Le Roux (1994) used the four closest neighbours at a given location, and developed a complex procedure based on weighted vectors to define vector trends. Poizot et al. (2006) chose semi-variogram geostatistics to assess the dilution of spatial autocorrelation of the studied variable (mean, sorting, skewness) as a function of the spacing between sample points. Since it can be used to determine the distance at which no autocorrelation exists, this approach is considered to represent the best way of defining the characteristic distance.

\section{Choice of trend cases}

Using the three statistical parameters, eight different trend cases can be formulated. In their pioneering work, McLaren (1981) and later Gao and Collins (1992) argued that two trend cases, i.e. $\mathrm{FB}-$ and $\mathrm{CB}+$, have the highest probability of occurring in the natural environment. Gao (1996) combined FB- and $\mathrm{CB}+$ to define trend vector fields. However, other studies have shown that, under particular conditions, different trend cases can be found (e.g. Gao et al. 1994; Asselman 1999; Carriquiry and Sánchez 1999; Carriquiry et al. 2001; Ríos et al. 2002). All possible trend cases were thus investigated in a methodical approach.
Spatial autocorrelation can provide information on the spatial structure of the variables based on geostatistical methods such as the commonly used Moran's index (Legendre and Legendre 1998). This index describes and quantifies the similarity between locations as a function of distance, enabling exploration of the distance (lag) at which the values of a given variable are spatially autocorrelated by taking the spatial location of the data points into account. In the present study, Moran's test was used to assess the spatial autocorrelation of the direction of the different vector fields. The vector field of a particular trend case exhibiting spatial autocorrelation was then considered as reflecting a real sediment transport process.

\section{Results}

Average disturbance depths of 3.3 and $4.3 \mathrm{~cm}$ were recorded using cores and rods with loose-fitting washers respectively. Evaluating the measurements from the disturbance rods, it was found that the thickness of mobilized sediments increased from the lower to the upper foreshore, i.e. the stoss side of the bar, and decreased on the bar top and the lee side. These data indicate sediment transport to the north, this being particularly evident within the first and second depth layers (i.e. $0-2$ and $2-4 \mathrm{~cm}$ ). The average position of the centroids was calculated to be about $40 \mathrm{~m}$, with values ranging from 35 to $52 \mathrm{~m}$.

To produce a finer grid than the original one, the distributions of the three textural parameters (mean size, sorting, and skewness) were interpolated using a geostatistical approach. The zero difference between the initial and the interpolated dataset was assessed using the non-parametric Wilcoxon test (Table 1). Within this refined grid the characteristic distance is defined as the distance at which the neighbouring samples are selected to determine the trend vector direction at each sample location. It is obtained from the semi-variogram of the three statistical parameters. The chosen minimum distance is equal to $35 \mathrm{~m}$ (Fig. 2).

The spatial distribution of mean grain size shows that, from the lower to the upper foreshore, the sediments on Camposoto beach evolve from coarse sand $(\approx 0.05$ phi) to

Table 1 Results of Wilcoxon test comparing mean, sorting and skewness between the initial and the interpolated datasets. No difference can be detected between the two datasets in terms of each statistical parameter tested $(\alpha=5 \%)$

\begin{tabular}{lll}
\hline Statistical parameters & $p$ value & Decision \\
\hline Initial vs. interpolated mean & 0.87 & Pass \\
Initial vs. interpolated sorting & 0.13 & Pass \\
Initial vs. interpolated skewness & 0.90 & Pass \\
\hline
\end{tabular}




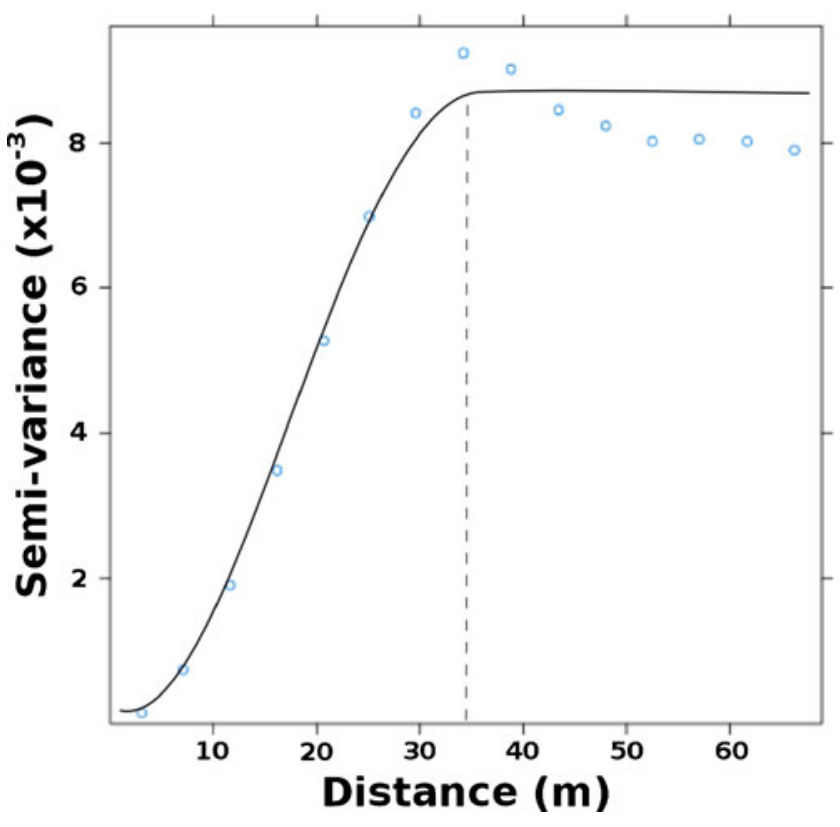

Fig. 2 Semi-variogram of standard deviation. Solid line Model used for kriging interpolation, circles experimental variogram, dashed line abscissa at $35 \mathrm{~m}$; at this distance, the semi-variogram reaches the threshold corresponding to the maximum variance distance

fine sand $(\approx 2.30 \mathrm{phi})$, the grain-size gradient increasing in the southern part of the study area (Fig. 3). Based on
Friedman (1967), the sediments are moderately sorted $(\approx 1.10 \mathrm{phi})$ on the lower foreshore and become very well sorted $(\approx 0.23$ phi) on the upper foreshore (Fig. 4). The sorting parameter evolves more regularly than the mean grain size, the gradient remaining almost constant throughout the study area.

The spatial distribution of skewness shows a more complicated pattern (Fig. 5). Two-thirds of the study area in the southern sector exhibits negative skewness. Schematically, this sector is delimited by a zone where the size distributions are very negatively skewed (ca. -0.35 ). This zone runs parallel to the coast in the south, and then bends gently to the north while approaching the coast. On each side of this zone, the size distributions become more negatively (or coarser) skewed. In the northern third of the study area, by contrast, the size distributions are more strongly positively (or finer) skewed $(\approx 0.35)$.

During the field survey, constructive swell approached from the SW and wave fronts formed a small angle with the coastline. The action of plunging and surging breakers on the beach face gave rise to shore-parallel currents (flowing north-westwards) with a mean velocity of $5.6 \mathrm{~cm} \mathrm{~s}^{-1}$. The tracer dispersion pattern clearly reflected this current, the centroid of fluorescent tracers being located northeast of the injection point owing to the combined effect of currents and flood tides (Bellido et al. 2011). The results of the Moran's

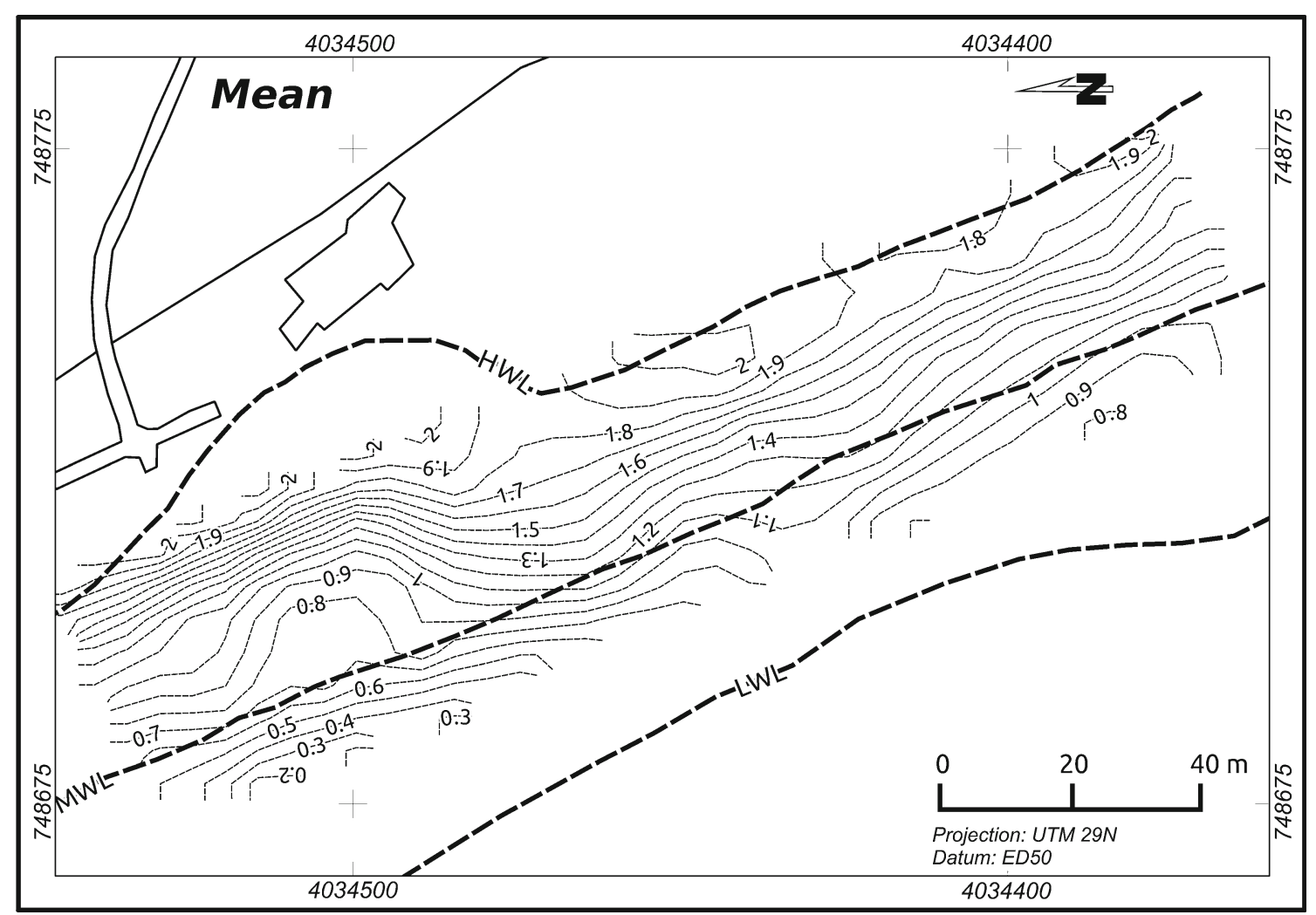

Fig. 3 Distribution of mean grain sizes (phi) on Camposoto beach 


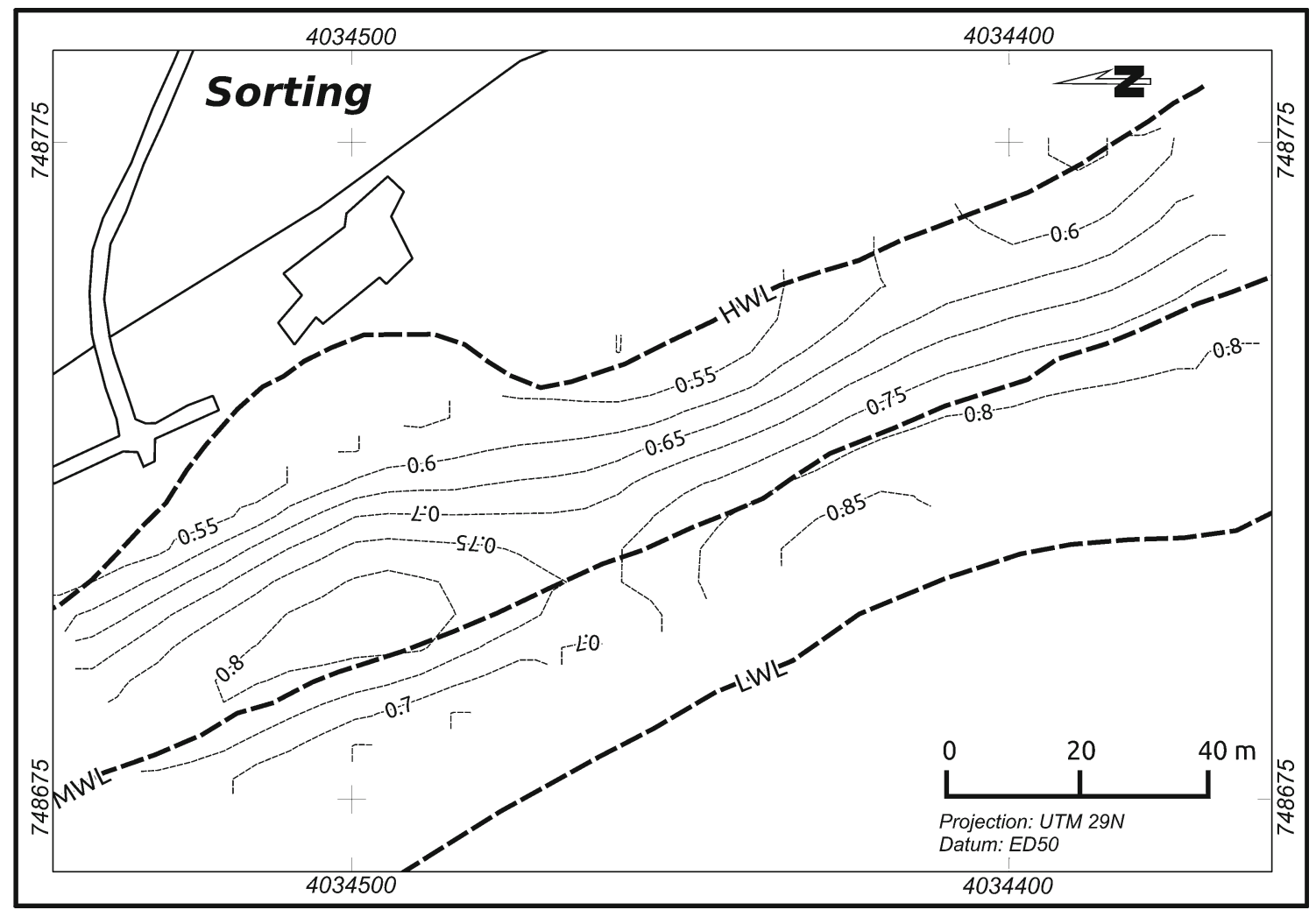

Fig. 4 Trend of the sediment sorting parameter (phi) on Camposoto beach

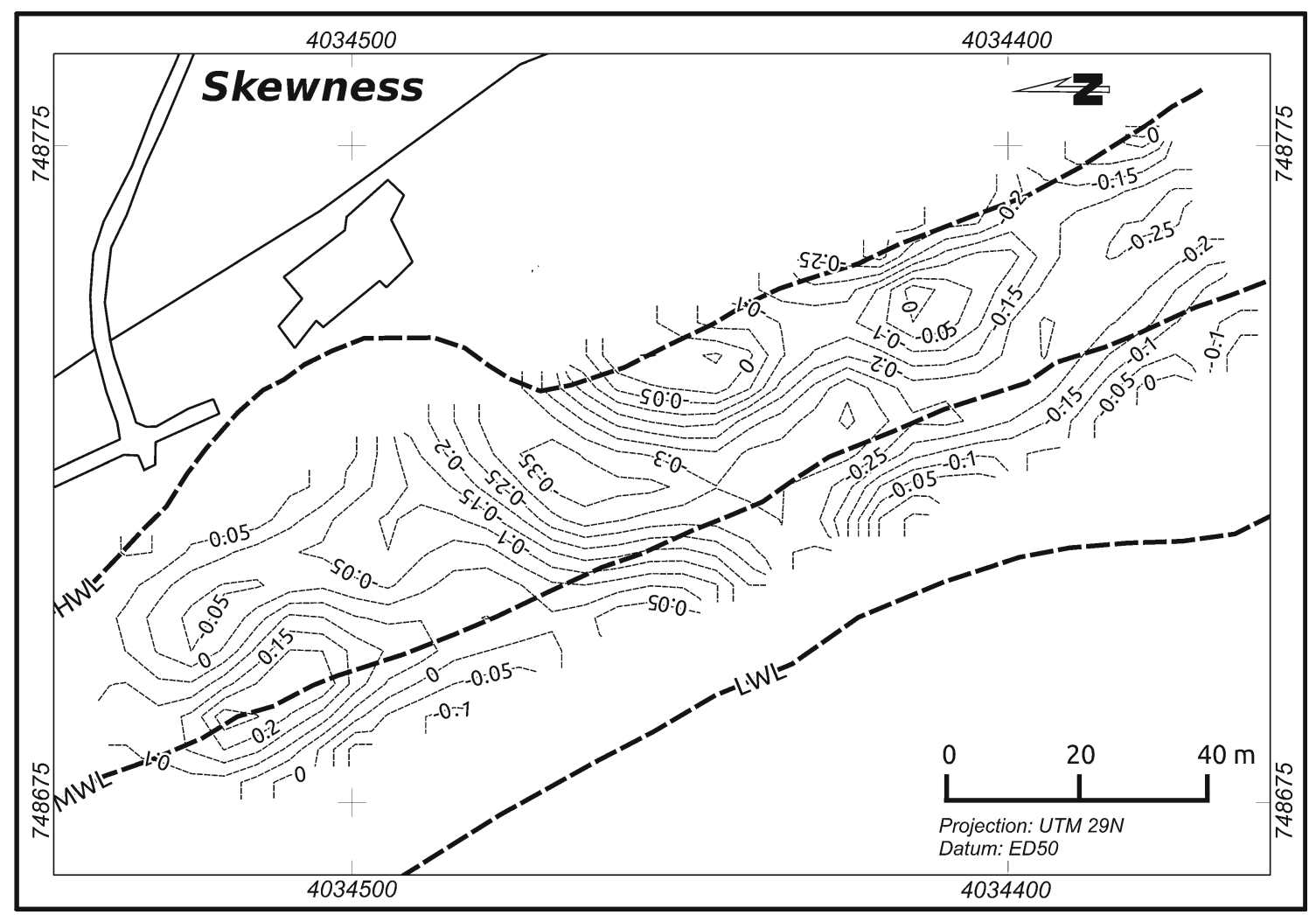

Fig. 5 Trend of the sediment skewness parameter on Camposoto beach 
Table 2 Results of Moran's I test on vector field trend cases ( $\alpha=5 \%$ ). Spatial autocorrelation of the vector direction cannot be excluded for FB- and FB+ trends

\begin{tabular}{lll}
\hline Vector trend case & $p$ value & Decision \\
\hline FB-: Finer, better sorted, more negatively skewed & 0.1607 & Pass \\
FB+: Finer, better sorted, more positively skewed & 0.0896 & Pass \\
FP-: Finer, more poorly sorted, more negatively skewed & 4.05 e-05 & Fail \\
FP+: Finer, more poorly sorted, more positively skewed & 8.05 e-15 & Fail \\
CB-: Coarser, better sorted, more negatively skewed & 2.20 e-16 & Fail \\
CB+: Coarser, better sorted, more positively skewed & 2.10 e-13 & Fail \\
CP-: Coarser, more poorly sorted, more negatively skewed & 3.40 e-10 & Fail \\
CP+: Coarser, more poorly sorted, more positively skewed & 0.0048 & Fail \\
\hline
\end{tabular}

test (Table 2) show that only the FB+ and FB- trend cases can be considered as reflecting real sediment transport processes, as they exhibit the best spatial autocorrelation of the vector fields.

Following the GSTA method of Poizot and Méar (2008), the variation of the vector length is a function of the confidence level associated with the transport in the corresponding vector direction, i.e. the longer the vector, the higher the confidence. Figure 6 shows the trend of the vector field computed for the FB- case. Overall, the vector directions are oriented onshore (W-SW to E-NE), which is in accordance with the dispersion of tracers and the combined effect of currents and flood tides described above. Therefore, the northern part of the study area is characterized by vectors which gradually turn towards the SE when approaching the high-tide level. In the southern part of the study area, the lower beach is characterized by vectors of high modulus (constancy). Closer to the high-tide level, the vector modulus decreases strongly. The FB-trend vectors with the highest modulus are positively correlated with the beach slope gradient, i.e. the steeper the slope, the higher the modulus value.

The FB + trend vector field is shown in Fig. 7. Vector directions are generally oriented onshore, almost identical to

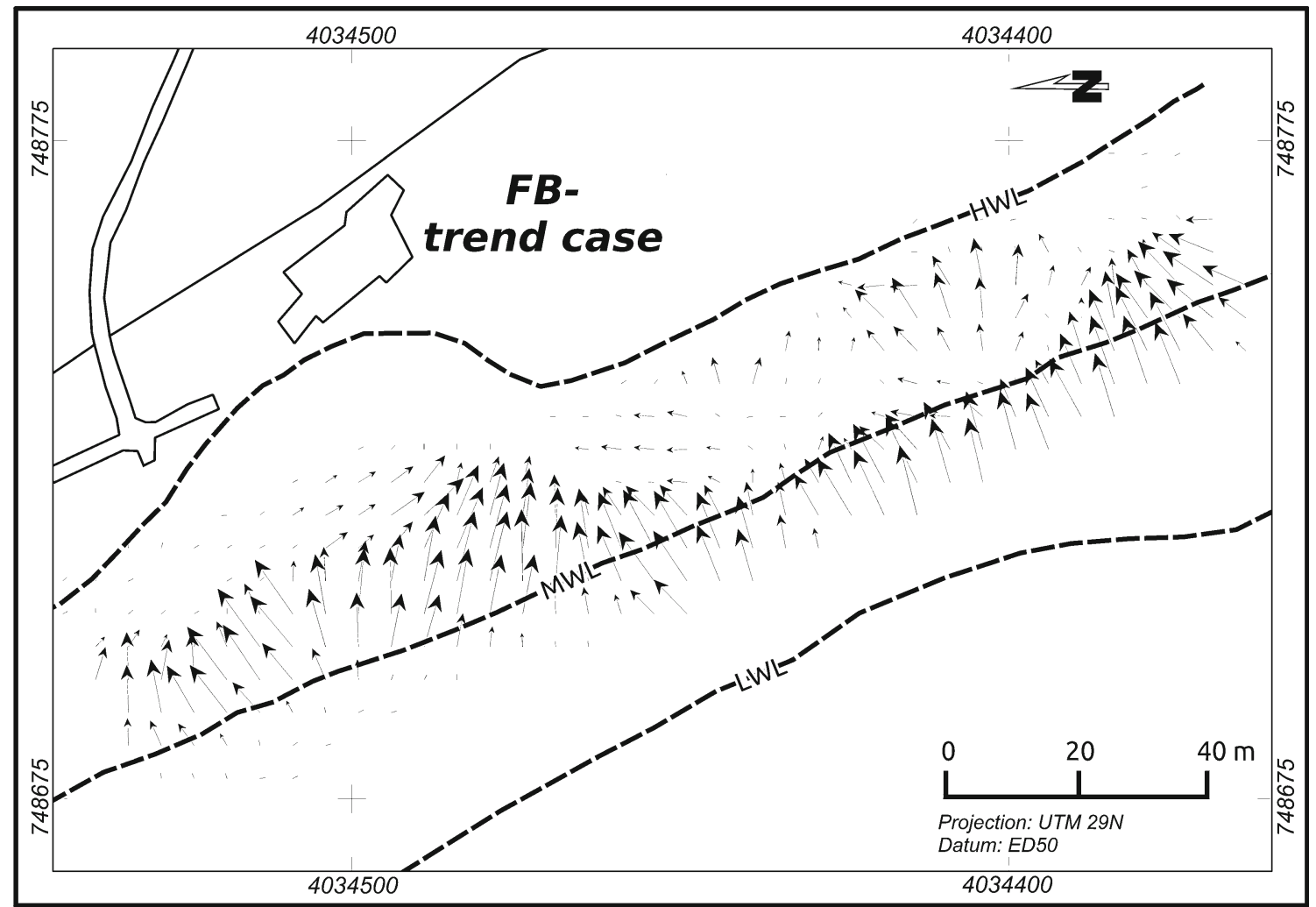

Fig. 6 Trend vector field of the FB- case: sediments become finer, better sorted and more negatively skewed. The vector length corresponds to the confidence level attributed to the direction of transport (the longer the vector, the higher the confidence level) 


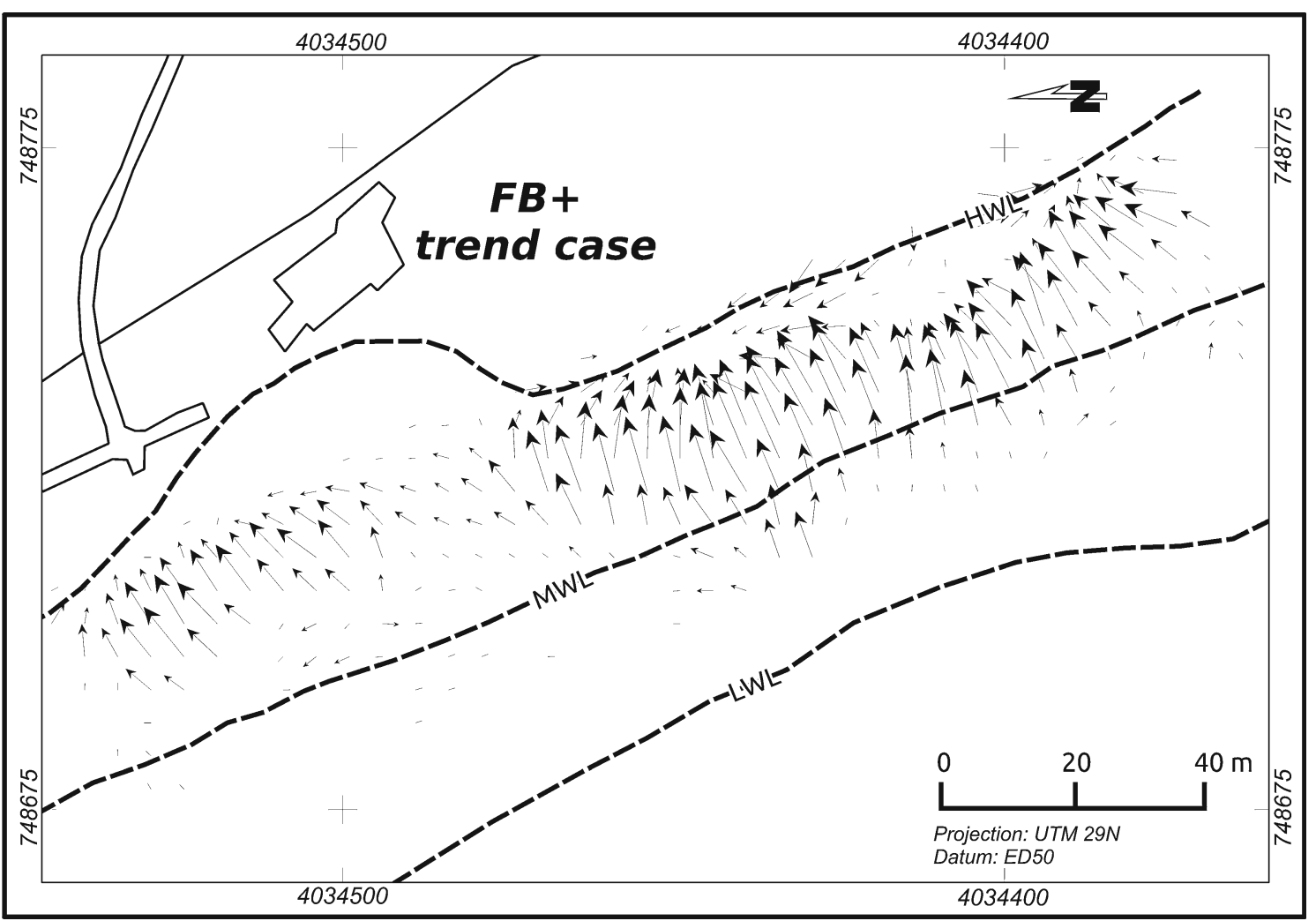

Fig. 7 Trend vector field of the FB+ case: sediments become finer, better sorted and less negatively or more positively skewed. The vector length corresponds to the confidence level attributed to the direction of transport (the longer the vector, the higher the confidence level)

the FB- trend case. However, the modulus values of the $\mathrm{FB}+$ and $\mathrm{FB}-$ vectors are negatively correlated, i.e. the

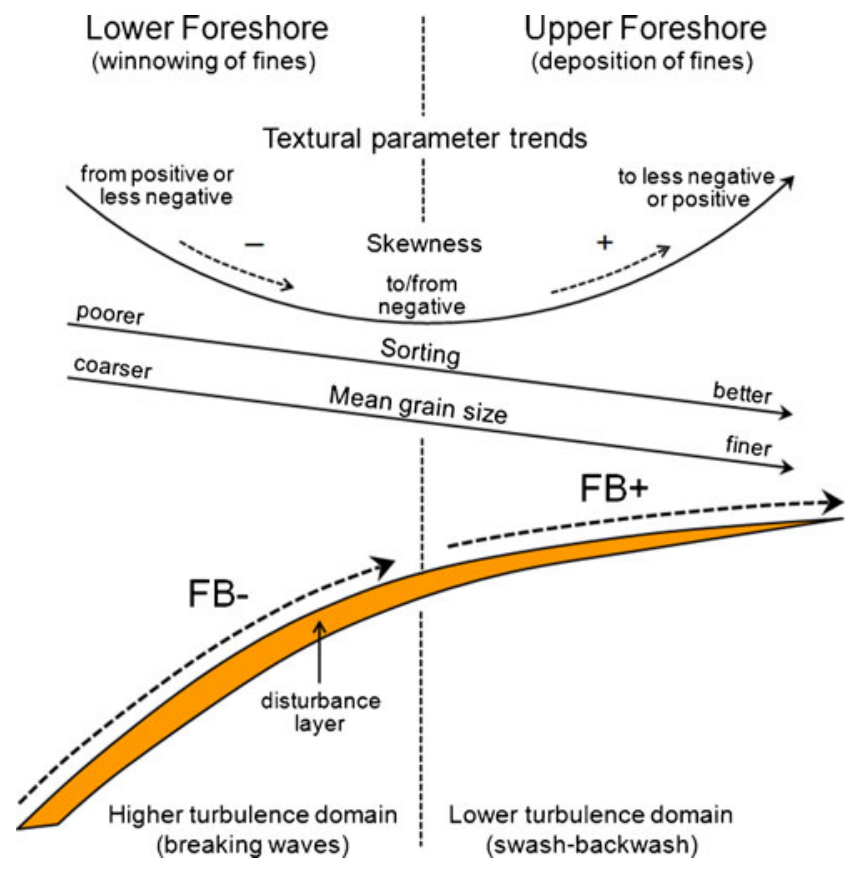

Fig. 8 Conceptual model of a shore-normal cross-section of the beach in the study area: the FB- trend characterizes the lower foreshore, the $\mathrm{FB}+$ trend the upper foreshore vector length of $\mathrm{FB}-$ is inversely proportional to the vector length of $\mathrm{FB}+$.

\section{Discussion and conclusions}

The FB- and FB+ cases differ only by the sign of their skewness. It has long been recognized that negative skewness is related to the intensity and duration of high-energy hydrodynamic conditions, which lead to the removal of fines (swash and backwash) - e.g. Sahu (1964), Martins (1965), Friedman (1967), Awasthi (1970) and Cronan (1972). Negative skewness can also be caused by the addition of coarser material such as shell fragments (e.g. Martins 1965). In this latter case, the sediment represents a mixture of two or more grain-size populations. Duane (1964) suggested that negative skewness is produced by the winnowing action of the fluid, whereas sands deposited in sheltered environments are dominantly more positively skewed.

The results of this study are in good agreement with the patterns of erosion/accretion recorded by Bellido et al. (2011) on the same beach. As observed by those authors, erosion takes place on the lower foreshore and accumulation on the upper foreshore. The former is composed of very coarse $(\approx-0.14$ phi) to medium sand $(\approx 0.42$ phi). Thus, the FB- trend case, located mostly on the lower foreshore, 
results from the removal of the finest particles of the sediment due to high turbulence, whereas the $\mathrm{FB}+$ trend case, located mostly on the upper foreshore, is a consequence of the deposition of previously eroded fines under less turbulent hydrodynamic conditions (Fig. 8).

In conclusion, the grain-size trend analysis applied to a granulometric dataset obtained on Camposoto beach (Spain) confirmed that, at the time of the study, the beach was undergoing accretion, a trend also observed by means of other independent reliable methods. An autocorrelation test based on the Moran's I index was used to assess the validity of vector direction. It was applied within the frame of a STA $^{\circledR} /$ GSTA approach for the first time and revealed two trend cases: (1) FB-, in which sediments become finer, better sorted and more negatively skewed, and (2) FB+, in which sediments become finer, better sorted and less negatively or more positively skewed.

Under the environmental conditions which prevailed during the fieldwork carried out by Bellido et al. (2011), the GSTA approach successfully explained the sediment transport direction over most of the area. In the present study, it was demonstrated for the first time that the $\mathrm{FB}+$ trend case can be used to reconstruct the direction of sand transport on a beach. This trend case was not selected in earlier studies applying STA ${ }^{\circledR}$ and GSTA to investigate sediment transport. It is therefore proposed that an exploratory approach should be conducted within the framework of GSTA to investigate all possible trend cases before adopting the most representative transport vector(s). This can be achieved by assessing the autocorrelation of vector field directions using a statistical test such as the index I of Moran.

It is emphasized that the GSTA procedure used in this study resulted in the reliable identification of sediment transport directions on Camposoto Beach. The method is less complicated and, hence, less time consuming than other methods, e.g. tracer studies. For this reason alone it is a viable and costeffective alternative for beach erosion management in general, and for the planning and design of beach nourishment works and the installation of hard protection structures in particular.

Acknowledgements This work is a contribution to the RESISTE Research Project (CGL200800458/BTE, Spanish Ministry of Science $\&$ Technology and F.E.D.E.R.) and to the Andalusia Research Group no. RNM-328. This investigation was partially developed at the Centro Andaluz de Ciencia y Tecnología Marinas (CACYTMAR, Junta de Andalucia-UCA), Puerto Real (Cádiz, Spain). The authors thank M.S.N. Carpenter for substantial language corrections. Also acknowledged are constructive comments by two anonymous referees and the editor B.W. Flemming.

\section{References}

Anfuso G (2005) Sediment-activation depth values for gentle and steep beaches. Mar Geol 220:101-112
Anfuso G, Dominguez L, Gracia F (2007) Short and medium-term evolution of a coastal sector in Cadiz, SW Spain. Catena 70:229 242

Asselman NEM (1999) Grain-size trends used to assess the effective discharge for floodplain sedimentation, river Waal, the Netherlands. J Sediment Res 69(1):51-61

Awasthi AK (1970) Skewness as an environmental indicator in the solani river system, roorkee (India). Sediment Geol 4:177-183

Bellido C, Anfuso G, Plomaritis TA, Rangel-Buitrago N (2011) Morphodynamic behaviour, disturbance depth and longshore transport at Camposoto Beach (Cadiz, SW Spain). J Coast Res SI 64:35-39

Carriquiry J, Sánchez A (1999) Sedimentation in the Colorado river delta and upper gulf of California after nearly a century of discharge loss. Mar Geol 158:125-145

Carriquiry J, Sánchez A, Camacho-Ibar V (2001) Sedimentation in the northern gulf of California after cessation of the Colorado river discharge. Sediment Geol 144:37-62

Carter R (1988) Coastal environments: an introduction to the physical, ecological and cultural systems of coastlines. Academic, London

Castelle B, Le Corre Y, Tomlinson R (2008) Can the gold coast beaches withstand extreme events? Geo-Mar Lett 28(1):23-30. doi:10.1007/s00367-007-0086-y

Cronan DS (1972) Skewness and kurtosis in polymodal sediments from the Irish Sea. J Sediment Petrol 42(1):102-106

Duane DB (1964) Significance of skewness in recent sediments, western Pamlico Sound, North Carolina. J Sediment Petrol 34(4):864-874

EEA (2006) The changing face of Europe's coastal areas. Office for Official Publications of the European Communities, Luxembourg. European Environment Agency, Copenhagen, EEA Rep no 6

Finkl C, Kruempfel C (2005) Threats, obstacles and barriers to coastal environmental conservation: societal perceptions and managerial positionalities that defeat sustainable development. In: Gomes FV, Pinto FT, Neves Das L, Sena A, Ferreira O (eds) Proc 1st Int conf coastal conservation and management in the Atlantic and Mediterranean, 17-20 April 2005. University of Porto, Tavira, pp 3-28

Flor-Blanco G, Flor G, Pando L (2013) Evolution of the Salinas-El Espartal and Xagó beach/dune systems in north-western Spain over recent decades: evidence for responses to natural processes and anthropogenic interventions. Geo-Mar Lett 33(2/3). doi:10. 1007/s00367-012-0301-3

Fraile-Jurado P, Ojeda-Zújar J (2013) The importance of the vertical accuracy of digital elevation models in gauging inundation by sea level rise along the Valdelagrana beach and marshes (Bay of Cádiz, SW Spain). Geo-Mar Lett 33(2/3). doi:10.1007/s00367012-0317-8

Friedman G (1967) Dynamic processes and statistical parameters compared for size frequency distribution of beach and river sands. J Sediment Petrol 37(2):327-354

Gao S (1996) A FORTRAN program for grain-size trend analysis to define net sediment transport pathways. Comput Geosci 22(4):449-452

Gao S, Collins M (1992) Net sediment transport patterns inferred from grain-size trends, based upon definition of "transport vectors". Sediment Geol 80:47-60

Gao S, Collins M, Lanckneus J, De Moor G, Van Lancker V (1994) Grain size trends associated with net sediment transport patterns: an example from the Belgian continental shelf. Mar Geol 121:171-185

Garrison JR Jr, Mestas-Nuñez AM, Williams JR, Lumb LM (2012) Can beach dune ridges of the Texas gulf coast preserve climate signals? Geo-Mar Lett 32(3):241-250. doi:10.1007/s00367-0110263-x

Guillén J, Palanques A (1996) Short- and medium-term grain size changes in deltaic beaches (Ebro delta, NW Mediterranean). Sediment Geol 101:55-67 
Karl T, Knight R (1998) Secular trends of precipitation amount, frequency, and intensity in the United States. Bull Am Meteorol Soc 79(2):231-241

Komar P, Inman D (1970) Longshore sand transport on beaches. J Geophys Res 75:5514-5527

Le Roux J (1994) An alternative approach to the identification of net sediment transport paths based on grain-size trends. Sediment Geol 94:97-107

Legendre P, Legendre L (1998) Numerical ecology. Developments in environmental modelling, vol 20. Elsevier, Amsterdam

Martins LR (1965) Significance of skewness and kurtosis in environmental interpretation. J Sediment Petrol 35(3):768-770

Masselink G (1992) Longshore variation of grain size distributions along the coast of the Rhône delta, southern France: a test of the "McLaren model". J Coast Res 8:286-291

Masselink G (1993) Longshore variation of grain size distributions along the coast of the Rhône delta, southern France: a test of the "McLaren model" - reply. J Coast Res 9(4):1142-1145

Masselink G, Buscombe D, Austin M, O'Hare T, Russell P (2008) Sediment trend models fail to reproduce small-scale sediment transport patterns on an intertidal beach. Sedimentology 55(3):667-687

McLaren P (1981) An interpretation of trends in grain size measures. J Sediment Petrol 51(2):611-624

McLaren P (1993) Discussion of: Masselink, G., 1992. Longshore variation of grain size distributions along the coast of the Rhône delta, southern France: a test of the "McLaren model". J Coast Res 9(4):1136-1141

McLaren P, Bowles D (1985) The effects of sediment transport on grain-size distributions. J Sediment Petrol 55(4):457-470

Muñoz JBL, Gutiérrez J, Moreno L, Cuena G (2001) Cost of beach maintenance in the Gulf of Cadiz (SW Spain). Coast Eng 42:143-153
Pedreros R, Howa H, Michel D (1996) Application of grain size trend analysis for the determination of sediment transport pathways in intertidal areas. Mar Geol 135:35-49

Poizot E, Méar Y (2008) ECSedtrend: a new software to improve sediment trend analysis. Comput Geosci 34(7):827-837. doi:10.1016/j.cageo.2007.05.022

Poizot E, Méar Y (2010) Using a GIS to enhance grain size trend analysis. Environ Model Softw 25(4):513-525. doi:10.1016/j.envsoft.2009. 10.002

Poizot E, Mear Y, Thomas M, Garnaud S (2006) The application of geostatistics in defining the characteristic distance for grain size trend analysis. Comput Geosci 32(3):360-370. doi:10.1016/j.cage o.2005.06.023

Poore RZ, DeLong KL, Richey JN, Quinn TM (2009) Evidence of multidecadal climate variability and the Atlantic multidecadal oscillation from a gulf of Mexico sea-surface temperature-proxy record. Geo-Mar Lett 29(6):477-484. doi:10.1007/s00367-009-0154-6

Quantum GIS Development Team (2012) Quantum GIS Geographic Information System. Open Source Geospatial Foundation. http:// qgis.osgeo.org

Rangel-Buitrago N, Anfuso G (2011) Coastal storm characterization and morphological impacts on sandy coasts. Earth Surf Process Landf 36:1997-2010

Ríos F, Cisternas M, Le Roux J, Corréa I (2002) Seasonal sediment transport pathways in Lirquen Harbor, Chile, as inferred from grain-size trends. Invest Mar Valparaiso 30(1):3-23

Sahu BK (1964) Depositional mechanisms from the size analysis of clastic sediments. J Sediment Petrol 34(1):73-83

Sancho-García A, Guillén J, Ojeda E (2013) Storm-induced readjustment of an embayed beach after modification by protection works. GeoMar Lett 33(2/3). doi:10.1007/s00367-012-0319-6 